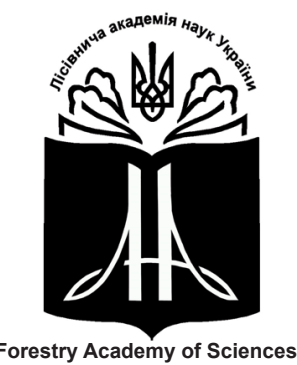

of Ukraine
Наукові праці Лісівничої академії наук України

Proceedings of the Forestry Academy of Sciences of Ukraine

http://fasu.nltu.edu.ua

https://doi.org/ 411704

Article received 2017.08.10

Article accepted 2017.11.15
ISSN 1991-606X print

ISSN 2616-5015 online

(a) $\triangle$ Correspondence author

Rimma Matveeva

selekcia@sibgau.ru

УДК 630.165.6

\title{
Результаты интродукции древесных растений в дендрарии Сибирского государственного университета (юг Средней Сибири)
}

\author{
О.Ф. Буторова', Р.Н. Матвеева²
}

\begin{abstract}
Приведены сведения о коллекичи интродуиеентов в дендрарии Учебно-опытного лесхоза Сибирского государственного университета науки и технологий им. акад. М. Ф. Решетнёва (СибГУ). Начало создания дендрария относится к 1948 г. В настоящеее время коллекичя представлена видами дальневосточной, европейской, сибирской, североамериканской флор, Японии и Китая. Коллекции ив и аллее лип придан статус «Памятника природы». В дендрарии произрастают редкие и исчезающие виды, нуждающиеся в охране и вошедшие в «Красную книгу СССР» (1978) - Princepia sinensis, a также в сводку «Редкие и исчезаюшие растения Сибири» (1980) - Euonymus maackii, Euonymus sacrosancta, Viburnum opulus, Tilia cordata, Hippophaё rhamnoides, Securinega suffruticosa, Padus avium, Malus baccata. Bblcombl древесньх видов варьируют в основном в пределах 8,0-19,0 м. Наибольшей высоты достигли Pinus sibirica, P. koraiensis, Picea obovata, Abies sibirica, Tilia cordata (20-23 м). Из семян, собранных в дендрарии, вырашчивается посадочный материал (сеяниы собственной репродукиии), которые используются для создания отделения вторичной интродукичии. Плодо(семе)ночение разной интенсивности отмечено у всех видов. Большинство из них находятся в хорошем состоянии, особенно интродуценты дальневосточной флоры. В группу со слабой жизненностью отнесены Amorpha fruticosa, Vitis amurensis, Quercus rubra, Acer platanoides, Mahonia aquifolium, Securinega suffruticosa.
\end{abstract}

Ключевые слова: интродукция, дендрарий, коллекция, флора, изменчивость, жизненность, плодоношение, семеночение, Сибирь

Введение. Научные исследования по интродукции древесных растений проводятся в разных регионах России и за рубежом. Так, коллекция интродуцентов в Центральном сибирском ботаническом саду (г. Новосибирск) широко представлена Т.Н. Встовской (Vstovskaja, 1985). Изучено также состояние интродуцентов в Сибирском ботаническом саду Томского государственного университета (Воуkо \& Kazarova, 2015), в Ботаническом саду Воронежской государственной технологической академии (Dorofeeva \& Popova, 2015), в северо-западной части Поль- ши (Kubus, 2008). Охарактеризована изменчивость интродуцентов в дендрарии Главного ботанического сада РАН (г. Москва) (Trusov, Yatsenko I., Risin, \& Yatsenko O., 2014), интродукционном в центре Калининградской области (Petrova \& Yakovleva, 2015) и др.

Объекты. Дендрарий СибГУ начал создаваться под руководством профессора Вальтера Эдуардовича Шмидта в 1948 г. Формированием маточного отделения интродуцентов, коллекции ив, тополей, кедровых сосен разного географического происхождения занимались первоначально

\footnotetext{
Буторова Ольга Федоровна - доктор сельскохозяйственных наук, профессор кафедры селекции и озеленения. Сибирский государственный университет науки и технологий имени академика М.Ф. Решетнева, пр. Мира, 82, г. Красноярск, 660049, Россия. Тел.: (391)227-58-09. E-mail: selekcia@sibgau.ru

2 Матвеева Римма Никитична - доктор сельскохозяйственных наук, профессор кафедры селекции и озеленения. Сибирский государственный университет науки и технологий имени академика М.Ф. Решетнева, пр. Мира, 82, г. Красноярск, 660049, Россия. Тел.: (391)227-58-09. E-mail: selekcia@sibgau.ru
} 
В.Э. Шмидт, Е.П. Верховцев, И.Ю. Коропачинский, О.П. Олисова. В дальнейшем исследования были продолжены под руководством ряда ученых (Matveeva \& Butorova, 2012, Romanova, 1996, Shestack \& Bozykova, 2006, Usova, 2015).

Дендрарий расположен в зеленой зоне г. Красноярска на левом берегу (второй террасе) Енисея (высота 250 м н.у. м.), в 40-41 кварталах Караульного лесничества, территория которого входит в Среднесибирский подтаежно-лесостепной район (List of forest ..., 2007). Дендрарий находится на склоне южной экспозиции крутизной $2-3^{\circ}$ и занимает в настоящее время площадь 8 га. Географические координаты: $56^{\circ}$ с.ш., $92^{\circ} 40^{\prime}$ в.д.

Преобладающие почвы - серые лесные легкосуглинистые слабооподзоленные. Пахотный горизонт характеризуется значительным содержанием гумуса (4,2-6,4\%). Сумма поглощенных оснований составляет 19,4-21,8 мг-экв. на 100 г почвы. Реакция почвенного раствора слабокислая ( $\mathrm{pH}$ солевое $=6,0-6,8)$. Содержание подвижных форм фосфора высокое (32,0-38,4 мг по Кирсанову), калия среднее (10,0-15,5 мг на 100 г почвы по Масловой).

В условиях юга Средней Сибири климат резко континентальный, характеризующийся сложным комплексом экзогенных факторов, которым растения подвергаются во время перезимовки. Ранние осенние и поздние весенние заморозки часто приводят к повреждению листьев, побегов, генеративных органов. Иногда наблюдается выжимание корневой системы растений при замерзании и оттаивании почвы. В районе исследований максимальная температура воздуха достигает $36{ }^{\circ} \mathrm{C}$, минимальная - минус $44^{\circ} \mathrm{C}$. Среднегодовая температура воздуха равна $0,6^{\circ} \mathrm{C}$. Сумма эффективных температур составляет $1400-2000^{\circ} \mathrm{C}$. Годовая сумма осадков в среднем равна 496 мм (Matveeva \& Butorova, 2012).

Цель исследований - на основании испытаний в течение продолжительного времени рекомендовать видовой состав древесных растений, пригодных для культивирования в суровых климатических условиях юга Средней Сибири.

Результаты исследований. В настоящее время коллекция интродуцентов включает инорайонные, местные виды и экотипы древесных растений. Важность и уникальность дендрария была отмечена еще в 1984 г., когда решением Исполкома Крайсовета от 19 декабря коллекции ив и аллее лип, произрастающих в дендрарии, был придан статус «Памятника природы», подлежащих тщательной охране.

В дендрарии представлена коллекция интродуцентов из Европы, Северной Америки, Китая, Японии, ДальнегоВостока. Многие интродуцированные растения акклиматизировались в суровых условиях и дают семенное потомство (Bratilova, Matveeva, Butorova \& Shcherba, 2015).

Коллекционные фонды дендрария ежегодно пополняются за счет сбора семян с отселектированных маточных растений, а также получения из других дендрариев и Ботанических садов (Барнаул, Екатеринбург, Липецк, Петроза- водск, Соликамск, Хабаровск, Нант (Франция), Таранд (Германия) и др.).

Растения различных флористических зон (Европы, Средней Азии, Сибири, Дальнего Востока, Китая, Японии, Северной Америки) произрастают в пяти маточных отделениях. Так, маточное отделение «А» создавалось в период с 1949 по 1963 гг. и занимает площадь 1,6 га. Здесь произрастают интродуценты, которые были высажены рядами на расстоянии 2,5-4 м друг от друга. Отделение «В» занимает площадь 0,8 га. Оно сформировано в 1961-1978 гг. на месте посевного отделения из оставшихся сеянцев и дополнительных посадок по рядовому принципу в четвертой и девятой секциях. Отделение «С», называемое «арборетумом», занимает площадь 0,8 га. Оно создано в 1953-1959 гг. по географическому принципу и насчитывает 40 видов. Отделение «Е» (европейско-сибирской флоры) площадью 1,12 га создавалось в ландшафтном стиле с 1960 г. Отделение «D» (дальневосточной флоры) площадью 0,84 га формировалось с 1970 г.

Коллекции ив и тополей созданы в 1961-1963 гг. под руководством И.Ю. Коропачинского, геопосадки Pinus sibirica Du Tour проведены в 19601985 гг. О.П. Олисовой, Р. Н. Матвеевой (Matveeva \& Butorova, 2012).

В коллекции находится большинство видов из флористических областей Голарктического царства (кроме Макаронезийской и Мадреанской), выделенных А.Л. Тахтаджяном (Tahtadzhjan, 1978). Растения относятся к 28 семействам, 66 родам. Распределение видов показало, что наибольшее представительство имеют семейства Розовые - 53 вида $(28 \%)$, Ивовые - 30 видов, а также гибриды (16\%). Единичными видами представлены семейства Актинидиевые, Вересковые, Ильмовые, Молочайные, Ореховые, Сумаховые.

Среди интродуцентов имеются редкие и исчезающие виды, подлежащие охране и вошедшие в «Красную книгу СССР» (1978) - Princepia sinensis Kom., а также в сводку «Редкие и исчезающие растения Сибири» (1980) - Euonymus maackii Rupr., E. sacrosancta Koidz., Viburnum opulus L., Tilia cordata L, Hippophaë rhamnoides L., Securinega suffruticosa Müll.Arg., Padus avium Mill., Malus baccata (L.) Borkh.

В отделении «А» наибольшую представленность имеют Pyrus communis L., Quercus mongolica Fisch., Q. robur L.; Amelanchier alnifolia Nutt., Pinus sibirica, Corylus heterophilla Fisch.ex Trautv., Malus baccata. Произрастают также Crataegus almaatensis Pojark., C. chlorosarca Maxim., Crataegus pinnatifida Bge.. Многие дальневосточные (Phellodendron aтurense Rupr., Pyrus communis L., Quercus mongolica Fisch., Juglans mandshurica Maxim.) и европейские (Quercus robur, Picea abies, Tilia cordata, Sorbus aucuparia L.) виды имеют высоту до 8,1-15,5 м. Слабым ростом характеризуется Quercus rubra, имеющий высоту не более 1,1 м, постоянно обмерзающий до уровня снежного покрова.

Особый интерес в этом отделении представляют растения Phellodendron amurense, Quercus robur и 
Q. mongolica, а также привитые растения Pinus sibirica и Pinus sylvestris L., выполненные способом «аблактировка» Е.П. Верховцевым в 1953 г.

В маточном отделении «В» произрастают представители флоры Дальнего Востока, Китая, Японии, Северной Америки, Европы, Сибири. Высота растений варьирует от 0,2 м (Mahonia aquifolium Nutt.) до 13,5-19,0 м (Quercus mongolica, Q. robur; Picea abies, Larix gmelinii Rupr., Tilia cordata, Juglans mandshurica). Здесь особое внимание привлекают Pinus pumila (Pall.) Regel, Pinus sibirica, Picea pungens Engelm., Juglans mandshurica. Высокими декоративными качествами отличаются Sorbus aucuparia, Picea abies, Juglans mandshurica, Padus maackii (Rupr.) Kom.

Отделение «С» состоит из видов восточноазиатской, европейской, североамериканской, сибирской флор. Наибольшим количеством экземпляров представлены Berberis amurensis Rupr., Picea obovata, Pinus sibirica и P. koraiensis; Tilia cordata, Rosa rugosa Thunb. Максимальную высоту имеют Pinus sibirica, P. koraiensis, Picea obovata, Abies sibirica Ledeb., Tilia cordata (20-23 м). В этом отделении перспективными являются Berberis amurensis, Juglans mandshurica, Thuja occidentalis L., Padus virginiana (L.) Mill., P. pensylvanica L., Armeniaca mandshurica (Maxim.) Skvortz..

В экспозиции отделения «Е» (евро-сибирской флоры) растут Juniperus sabina L., Ribes komarovii, Ulmus pumila, Quercus robur, Picea abies (L.) Karst., Viburnum lantana L. Наибольшей высоты (11-15 м) достигают деревья Picea obovata, Pinus sibirica, Tilia cordata, Larix sibirica Ledeb. Высокими декоративными качествами отличаются Viburnum lantana L., Cotinus coggygria Scop., Juniperus communis L., J. sabina; Pinus koraiensis.

Экспозиция Дальнего Востока (отделение «D») включает виды из восточноазиатской флористической области. Это отделение представлено Berberis amurensis, Phellodendron amurense, Quercus mongolica, Pinus koraiensis, Juglans mandshurica, Syringa amurensis Rupr., Princepia sinensis, Shepherdia argentea (Pursh.) Nutt., Eleutherococcus senticosus Maxim., Rhamnus davurica Pall., Acer mono Maxim., Cotoneaster lucidus Schlecht., Corylus mandshurica Maxim., Acer ginnala Maxim. Высота растений варьирует от 1,6 м (Vitis amurensis Rupr.) до 6-13 м (Padus maackii, Tilia mandshurica Rupr., Larix leptolepis Gord.). Bce виды дальневосточных роз (шиповники) имеют высоту 0,4-2,0 м, Ribes komarovii Pojark. $-1,8$ м.

Плантация тополей первоначально состояла из культиваров Populus x canadensis Moench (Populus x canadensis 'Marilandica', 'Regenerata', 'Robusta', 'Gelrica', 'Monilifera' и др.). На плантации ив произрастают виды и гибриды: Salix daphnoides Will., S. rubra Huds., S. viminalis L., S. purpurea L., $S$. pentandra L., S. dasyclados Vimm.и др.

Из семян, собранных в дендрарии, выращивают посадочный материал (сеянцы собственной репродукции), использованный для создания отделения вторичной интродукции. Важной задачей является определение адаптационных реакций видов на осно- ве оценки индивидуальной изменчивости морфологических признаков сформированных коллекций.

Плодоношение разной интенсивности отмечено у всех видов. Обильно плодоносят Berberis amurensis, Euonymus sacrosancta, Viburnum lantana, Frangula alnus Mill., Phisocarpus opulifolius Maxim., Syringa amurensis, S. josikaea Jacq., Pentaphilloides fruticosa (L.) Rydb., Malus baccata. Слабое плодоношение отмечается у Aronia melanocarpa (Michx.) Elliot., Euonymus verrucosa Scop., Quercus robur, Tilia platyphyllos Scop., T. cordata; Prunus ussuriensis Koval.et Kostina, Ribes alpinum L., R. komarovii; Sorbus aucuparia, Padus virginiana. При оценке жизненности имеющихся видов выявлено, что большинство из них находятся в хорошем состоянии. В группу со слабой жизненностью отнесены Amorpha fruticosa L., Vitis amurensis, Quercus rubra, Acer platanoides L., Mahonia aquifolium, Securinega suffruticosa (Matveeva \& Butorova, 2012).

Наибольшей пылезадерживающей способностью отличаются Ulmus pumila L., Sorbus aucuparia, Cotoneaster lucidus, Berberis vulgaris L., Phisocarpus opulifolius. К сернистому ангидриду устойчивы Acer negundo L., Rosa rugosa; среднеустойчивы - Hippophaё rhamnoides, различные виды Populus, Malus baccata, Populus alba L., Swida alba (L.) Opiz. активно поглощают сернистый газ в начале периода вегетации Caragana arborescens Lam., в конце - Tilia cordata. Без значительных повреждений Ulmus pumila выдерживает до 1,78 г фтора на 1 кг сухой массы, тополь бальзамический - до 1,06, Sorbus aucuparia - до 1,05 г (Stepen \& Repyakh 1998, Sedih , 2000).

Устойчивым к радиоактивному загрязнению является Acer negundo L. Облучение влажных семян данного вида дозой до 10 тыс. рентген не понижало их всхожести, в то время как для семян Pinus sibirica такой же влажности летальной явилась доза 400 рентген (Matveeva \& Butorova, 2001). Нетребовательными к почвенному плодородию являются Populus balsamifera L., Caragana arborescens Lam., Ulmus pumila. Высокой засухоустойчивостью обладают Betula pendula Roth., Ulmus pumila, Berberis vulgaris, Ribes aureum Pursh. К зимо-, засухо- и газоустойчивым древесным растениям относятся Berberis amurensis, Euonymus verrucosa с яркими красными, розовыми плодами; Cotoneaster lucidus с декоративной кроной, хорошо переносящей стрижку. Теневыносливыми и газоустойчивыми являются Corylus heterophilla, Pentaphilloides fruticosa (цветет с июня до поздней осени); засухо-, газоустойчивыми - Rosa glauca Pourr. (с красновато-сизыми листьями, розовыми цветками, красными плодами), Padus pensylvanica (дерево высотой до 13 м с красными съедобными плодами). Ценными источниками для получения растительного сырья, используемого в фармацевтической и дубильной промышленности, являются Euonymus maackii, E. sacrosancta; Viburnum opulus, Pentaphilloides fruticosa, Schisandra chinensis Baill., Sorbus aucuparia, виды Crataegus (Vstovskaja, 1985).

Коллекция включает большой ассортимент декоративных, лекарственных, медоносных, плодовых растений. Среди растений, образующих съедобные 
плоды (семена), большой интерес представляют Aronia melanocarpa, Prunus divaricata Ldb., Pyrus communis, Amelanchier alnifolia, Viburnum lantana, Pinus sibirica, Corylus heterophilla, Juglans mandshurica, Princepia sinensis, Prunus divaricata Ldb., P. ussuriensis, Ribes aureum, R. rubrum L., R. nigrum L., Padus virginiana, $P$. avium.

K наиболее декоративным растениям следует отнести Armeniaca mandshurica (Maxim.) Skvortz., Berberis amurensis, B. vulgaris, Phellodendron amurense, Euonymus verrucosa, Cerasus japonica (Thunb.) Lois., Picea pungens, Rhamnus davurica, Rhamnus ussuriensis Ja. Vassil., Lonicera xylosteum L., L. tatarica L., Corylus mandshurica, Tilia mandshurica, Elaeagnus argentea Pursh., Mahonia aquifolium, Amygdalus nana L., Cotinus coggygria Scop., Phisocarpus opulifolius, Sorbus aucuparia, Sorbaria sorbifolia A.Br., Swida alba (L.) Opiz., Ribes alpinum, Symphoricarpos albus B1., Spiraea salicifolia L., S. margaritae Zbl., S. media Fr. Schmidt., S. nipponica Maxim.; Padus pensylvanica, Philadelphus tenuifolius Rupr. et Maxim., Shepherdia argentea (Pursh.) Nutt., Malus sieversii (Ledeb.) M.Roem., различные виды родов клен, роза, сирень.

В последнее время большое внимание уделяется разведению вечнозеленых хвойных видов, в частности, можжевельников, туи, кипарисовика, которые достаточно широко используются в озеленении европейской части России и могут использоваться не только для озеленения городов Сибири, но и производственных, жилых помещений, так как являются одними из самых фитонцидных растений, обладающих высокими санитарно-гигиеническими и декоративными свойствами. Известно, что в помещении одно растение можжевельника за сутки может полностью уничтожить болезнетворную микрофлору.

Большой промышленной ценностью отличаются культуры Pinus sibirica, являющегося одной из основных лесообразующих пород Сибири, древесина и семена («кедровые орешки») которого являются ценным сырьем в исследуемом регионе (Matveeva \& Butorova, 2012).

Для создания живых изгородей в наших условиях можно рекомендовать Ulmus pumila, Caragana arborescens, C. frutex (L.) C. Koch., Cotoneaster lucidus, Syringa josikaea, Ribes lucidum Kit, а также разные виды Spiraea L.

Для оформления беседок, стен, оград целесообразно применять Vitis amurensis, Parthenocissus quinquefolia Planch.

Заключение. В условиях г. Красноярска и прилегающей зеленой зоны можно широко использовать Quercus mongolica, Q. robur; Abies sibirica, Picea abies, P. obovata, Pinus sibirica, P. koraiensis, Padus maackii, различные виды родов Tilia, Larix, Fraxinus, прошедшие испытания в течение продолжительного времени в дендрарии СибГУ.

\section{Библиографические ссылки}

Boyko, G.A., \& Kazarova, S. Yu. (2015). Arboretum of the Botanical Garden the Moscow University and its development prospects. Problems of the study of vegetation of Siberia: materials of the 5 international scientific conference, 20-22 okt. Tomsk, Russia (in Russian).

Bratilova, N.P., Matveeva, R. N., Butorova, O.F., \& Shcherba J.E. (2015). The features the growth of 17-46 jears old Pinus sibirica tees of different geographic origin. Proceedings of the Forestry Academy of sciences of Ukraine, 13. 59-62 (in Russian).

Dorofeeva, V.D., \& Popova, V.T. (2015). The problem of preserving the biodiversity of plants in the Arboretum VSFTA. Forest ecosystems in a changing climate: проблемы и перспективы : The materials of the international scientific and technical conference, 21-22 may. Voronezh, Russia (in Russian).

Kubus, M.A. (2008). Collection of the dendrological garden in Glinna (Northwest Poland). Not. bot. horti agrobot,36, (2), 28-31.

Matveeva, R. N. \& Butorova, O.F. (2001). Accelerated growing of seedlings and Siberian cedar cultures in Eastern Siberia. Krasnoyarsk: SSTU (in Russian).

Matveeva, R. N. \& Butorova O.F. (2012). Arboretum SSTU. Krasnoyarsk: SSTU (in Russian).

List of forest vegetation zones (2007). Order N 68 «On approval of the list of forest vegetable zones and forest areas of the Russian Federation». Moskau (in Russian).

Petrova, N.G., \& Yakovleva, T.A. (2015). Woody plants of the Siberian introduction Center in dendroflora in the Kaliningrad region. The Herald BFU, 7, 38-45 (in Russian).

Romanova, A.B. (1996). Features of vegetation far East flora in Arboretum of KSTU. Processing of raw materials and plant waste, 23, 73-80 (in Russian).

Sedih, T. V. (2000). Green plantings of Krasnoyarsk. Continuous environmental education and ecological problems of the Krasnoyarsk region. 61-63 (in Russian).

Stepen, R.A., \& Repyakh, S.M. (1998). Volatile Terpenoids of pine forests. Krasnoyarsk: SSTU (in Russian).

Tahtadzhjan, A. L. (1978). Floral area of Earth. Leningrad: Science (in Russian).

Trusov, N.A., Yatsenko, I.O., Risin, S.L., \& Yatsenko, O.V. (2014). The main problems when working with collections in the age of Arboretums and their solutions (for example, the collection of Betula L. in the Arboretum of RAS). Subtropical and ornamental horticulture, 51, 55-62 (in Russian).

Shestack, K. V. \& Bozykova, L. G. (2006). Study of the variability of seed progeny in the Arboretum SSTU. Gardening, seed growing, introduction of woody plants, 174-176 (in Russian).

Vstovskaja, T.N. (1985). Woody plants - aliens in Siberia. Novosibirsk: Nauka (in Russian).

Usova, E.A. (2015). Seed reproduction of plant introductions of the Eastern in the Arboretum SSTU. Gardening, seed growing, introduction of woody plants, 94-97 (in Russian). 


\section{Результати інтродукції деревних рослин у дендрарії Сибірського державного університету (південь Середнього Сибіру)}

\author{
О.Ф. Буторова' , Р. Н. Матвєєва²
}

Наведено дані про колекції інтродуцентів у дендрарії Навчально-дослідного лісгоспу Сибірського державного університету науки і технологій ім. акад. М.Ф. Решетньова (СибДУ). Початок створення дендрарію припадає на 1948 р. Тепер колекція представлена видами далекосхідної, європейської, сибірської, північноамериканської флор, Японії і Китаю. Колекції верб і алеї лип надано статус «Пам'ятника природи». У дендрарії ростуть рідкісні та зникаючі види, що потребують охорони, які занесено до «Червоної книги СРСР» (1978) - Princepia sinensis, а також до каталога «Рідкісні та зникаючі рослини Сибіру» (1980) - Eиопути maackii, Euonymus sacrosancta, Viburnum opulus, Tilia cordata, Hippophae rhamnoides, Securinega suffruticosa, Padus avium, Malus baccata. Висоти деревних видів варіюють в основному в межax 8,0-19,0 м. Найбільшої висоти досягли деревні види - Pinus sibirica, P. koraiensis, Picea obovata, Abies sibirica, Tilia cordata (20-23 м). 3 насіння, зібраного у дендрарії, вирощують садивний матеріал (сіянці власної репродукціі), які використовують для створення відділення вторинної інтродукції. Плодоношення та насіннєношення різної інтенсивності відзначено у всіх видів. Більшість 3 них перебувають у доброму стані, особливо - інтродуценти далекосхідної флори. До групи зі слабкою життєвістю віднесено Amorpha fruticosa, Vitis amurensis, Quercus rubra, Acer platanoides, Mahonia aquifolium, Securinega suffruticosa.

В умовах м. Красноярська і прилеглої зеленої зони можна широко використовувати Quercus mongolica, Q. robur; Abies sibirica, Picea abies, P. obovata, Pinus sibirica, P. koraiensis, Padus maackii, різні види родів Tilia, Larix, Fraxinus, які пройшли випробування впродовж тривалого періоду часу в дендрарії СибДУ

Ключові слова: інтродукція, дендрарій, колекція, флора, мінливість, життєвість, плодоношення, насіннєношення, Сибір

\section{Studies on introduction of tree plants in the Arboretum (South Central Siberia) of the Siberian State University}

\author{
O. Butorova', R. Matveeva²
}

The information about the collections of introduced plants, growing in Arboretum of Training and Experienced Forestry SibSU presented, it is generated from 1948 under the leadership of Walter Eduardovich Schmidt. The importance and recognition of the Arboretum, which given the status of a "Monument of nature" is stressed, Originally it was the collection of Yves and alley of Linden trees, later-in the year 2000 - for Arboretum. The Arboretum is situated in a green area of Krasnoyarsk at an altitude of $250 \mathrm{~m}$ above sea level on the territory of the Karaulnyii of Training and experienced Forestry SibSU (green area of Krasnoyarsk). The soil in the Arboretum is grey forest light loamy weak podsol. Climate is sharply continental. The air temperature ranges from plus 44 to minus $36^{\circ} \mathrm{C}$. Annual precipitation is $496 \mathrm{~mm}$. The species in the different branches of the Arboretum described which are, representing the far eastern, European, North American flora. Marked by rare and endangered species listed in the «Red Book of the USSR» (Princepia sinensis), a summary of the «Rare and endangered plants of Siberia» (Euonymus maackii, Euonymus sacrosancta, Viburnum opulus, Tilia cordata, Hippophae rhamnoides, Securinega suffruticosa, Padus avium, Malus baccata). The species in the different branches of the Arboretum highlighted, which differ most intense growth (Pyrus communis, Quercus mongolica, Quercus robur, Larix gmelinii, Tilia cordata, etc.) and weak growth (Quercus rubra, Padus virginiana). When evaluating the viability of existing species that most of them are revealed in good condition. In the group with low vitality they are Amorpha fruticosa, Vitis amurensis, the Quercus rubra, Acer platanoides l., Mahonia aquifolium, Securinega suffruticosa. Also species Listed that differ most ability dust delay, active absorption of sulfur dioxide, resistance to radioactive pollution, drought-tolerance, decorative. The Recommendations on the use of certain species to form arbors, fences, creating hedges were presented. For landings under conditions of Krasnoyarsk and nearby green zone recommended many species, including Quercus mongolica, $Q$. robur; Picea abies, P. obovata, Padus maackii, different types of lime, larch, an ash-tree, etc.

Key words: introduction, Arboretum, collection, flora, variability, vitality, fruiting, seed, Siberia

\footnotetext{
Butorova Olga Fedorovna - doctor of Agricultural Sciences, Professor of plant breeding and gardening. Siberian State University of science and technology named after academician M.F. Reshetnev, pr. Mira, 82, Krasnoyarsk, 660049, Russia. Тел.: (391)227-58-09. E-mail: selekcia@sibgtu.ru

Matveeva Rimma Nikitichna - doctor of Agricultural Sciences, Professor of plant breeding and gardening. Siberian State University of science and technology named after academician M.F. Reshetnev, pr. Mira, 82, Krasnoyarsk, 660049, Russia. Тел.: (391)227-58-09. E-mail: selekcia@sibgtu.ru
} 